\title{
ANÁLISE DA COMPOSIÇÃO CENTESIMAL DO PÓ DAS FOLHAS DE OITICICA (Licania rigida Benth.)
}

Janaina de Carvalho Alves'; Iraíldo Francisco Soares ${ }^{2}$; Karina Lizzeth Pedraza Galvan ${ }^{1}$; Madian Johel Galo Salgado1; Fernanda Antônia de Souza Oliveira1; Michele Alves de Lima3; Sergio Eduardo Soares ${ }^{1}$; Robson Alves da Silva4; Julianne Viana Freire Portela ${ }^{5}$

${ }^{1}$ Universidade Federal da Bahia, Faculdade de Farmácia, Salvador, Bahia, Brazil; janainatotustuus@outlook.com

2Universidade Federal do Piauí, Departamento de Nutrição, Teresina, Piauí, Brazil.

${ }^{3}$ Instituto Federal de Educação, Ciencia e Tecnologia do Maranhão, Campus Caxias, Maranhão, Brazil.

${ }^{4}$ Instituto Federal de Educação Ciência e tecnologia do Piauí, Campus Teresina Central, Teresina, Piauí, Brazil.

Resumo: Licania rigida George Bentham é uma planta conhecida como oiticica que, em algumas regiões do Nordeste, apresenta aplicação medicinal. Objetivou-se avaliar a qualidade do pó das folhas da oiticica. As amostras foram coletadas em Picos/PI, higienizas e sanitizadas. Submetidas a secagem nas temperaturas $40^{\circ} \mathrm{C}, 50^{\circ} \mathrm{C}$ e $60^{\circ} \mathrm{C}$. O pó obtido foi submetido a analises de composição centesimal. Os percentuais de umidade foram 7,80, 7,89 e 7,01\%. Enquanto que cinzas: 10,24 10,16 e 10,64\%. Lipídios com teores $5,96 \pm 1,22 ; 4,42 \pm 0,75$ e $7,34 \pm 1,19$, para temperaturas $40{ }^{\circ} \mathrm{C}, 50$ ${ }^{\circ} \mathrm{C}$ e $60^{\circ} \mathrm{C}$, respectivamente. Proteínas e carboidratos apresentaram-se nos intervalos de 0,54 à 0,58 e 74,43 à 78,17 , respectivamente, não havendo diferença estatisticamente significativamente $(p<0,05)$. Conclui-se que o pó obtido em ambas as temperaturas possuem características adequadas segundo legislação vigente.

Palavras-Chave: Folhas; Oiticica; Composição Centesimal.

\section{ANALYSIS OF CENTESIMAL COMPOSITION OF POWDER OF SHEETS OF OITICICA (Licania rigida Benth.)}

Abstract: Licania rigida George Bentham is a plant known as delicious, which in some Northeastern regions has medicinal application. The objective of this study was to evaluate the dust quality of the leaves of the oiticica. The samples were collected in Picos/PI, sanitized. Submitted to drying at $40^{\circ} \mathrm{C}, 50^{\circ} \mathrm{C}$ and $60^{\circ} \mathrm{C}$. The obtained powder was subjected to analysis of centesimal composition. The humidity percentages ranged from 7,80, 7,89 e 7,01\%. While ashes, 10,24 10,16 e 10,64\%. Lipids with contents $5.96 \pm 1.22 ; 4.42 \pm 0.75$ and $7.34 \pm 1.19$, for temperatures $40^{\circ} \mathrm{C}, 50^{\circ} \mathrm{C}$ and $60^{\circ} \mathrm{C}$, respectively. Proteins and carbohydrates ranged from 0.54 to 0.58 and 74.43 to 78.17 , respectively, no statistically significant difference $(p<0,05)$. It is concluded that the powder obtained at both temperatures has adequate characteristics according to current legislation.

Keywords: Sheets; Oiticica; Centesimal composition. 


\section{INTRODUÇÃO}

A biodiversidade pode ser observada por meio dos seus valores evolutivos, ecológicos ou até mesmo como meios para a utilização direta ou indireta da sua capacidade para a humanidade. Neste acervo, encontra-se contido o conhecimento referente ao mundo vegetal com o qual várias comunidades estão em contato [1].

A busca e o uso de plantas com fins terapêuticos é uma atividade que vem de geração a geração, descritos com o intuito de preservar essa tradição milenar por meio das práticas fitoterápicas e complementares na saúde. Várias são as plantas que apresentam essa ação e são utilizadas a partir do conhecimento empírico [2].

A planta Licania rigida George Bentham (L. rigida Benth.) popularmente conhecida como oiticica, é característica da caatinga e concentra-se nas beiras das bacias hidrográficas nos estados do Piauí, Ceará, Rio Grande do Norte e Paraíba [3]. Em algumas regiões do Nordeste, apresenta aplicação medicinal, a partir do conhecimento popular, por meio do uso de suas folhas na formulação de chá para o tratamento da Diabetes Mellitus Tipo 2 [4].

Devido a grande procura por produtos naturais, as indústrias farmacêuticas de fitoterápicos recorrem a utilização do método da secagem em espécies medicinais, método esse que apresenta-se como uma operação singular no quesito de armazenamento do material vegetal, a fim de atender determinadas demandas, uma vez que essas empresas não possuem estrutura para utilizar-se de plantas frescas nas quantidades exigidas para a produção industrial. As fábricas têm utilizado o processo de secagem como uma das principais estratégias para preservação da qualidade dos produtos agrícolas [5].

A secagem aplicada em materiais vegetais consiste na remoção de grande parte de água contida no produto provocando redução da atividade de água desse gênero, inibindo o desenvolvimento de microrganismos e retardando deteriorações de origem físico-química. $O$ processo de secagem e seus protocolos variam de acordo com a parte da planta e espécie a ser utilizada, visando aumentar a eficiência desse método [6-7].

Durante o método de secagem, algumas propriedades nutritivas podem ser perdidas, em processos com tratamento térmico, todavia, muitas vantagens podem ser atribuídas à secagem, tais como: aumento da vida útil do produto; concentração do valor nutritivo devido à perda de água; facilidade no transporte e comercialização; a redução do peso do produto; a estabilidade dos componentes aromáticos; a proteção contra degradação enzimática e oxidativa; a economia de energia por não necessitar de refrigeração e a disponibilidade do produto durante qualquer época do ano [8-9-10].

Diante deste panorama, objetivou-se estudar a qualidade do pó obtido após a secagem das folhas de oiticica em três diferentes temperaturas.

\section{METODOLOGIA}

Está pesquisa foi realizada na Universidade Federal do Piauí - UFPI, nos Campus Senador Helvídio Nunes de Barros - CSHNB, Picos/PI e Campus Ministro 
Petrônio Portella - CMPP, Teresina/PI. As análises físico-químicas foram realizadas no Laboratório de Bromatologia e Bioquímica de Alimentos/CSHNB/UFPI, enquanto que as análises nutricionais ocorreram no Laboratório de Bromatologia/CMPP/UFPI.

As folhas da planta L. rigida, foram coletadas na flora do município de Picos/PI, nas estações da primavera e verão, entre os meses de outubro de 2016 a janeiro de 2017. As folhas foram colhidas sempre no turno da manhã entre $7 \mathrm{~h}$ e $8 \mathrm{~h}$, sendo em seguida armazenadas em plástico polietileno e acondicionas em isopor, para então serem transportadas até o local de realização das análises.

As folhas in natura de L. rigida Benth. foram separadas manualmente dos caules e resíduos existentes, lavadas em água corrente, sanitizadas com solução de

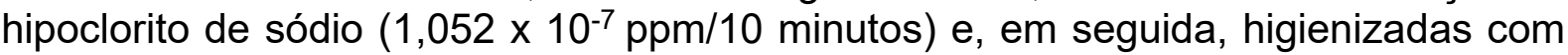
água destilada. Posteriormente, foram expostas sobre papel toalha, para retirada do excesso de água.

As amostras foram submetidas ao processo de secagem em desidratador Pratic Dryer ${ }^{\circledR}$ de leito fixo ascendente a três temperaturas $\left(40^{\circ} \mathrm{C}, 50{ }^{\circ} \mathrm{C}\right.$ e $\left.60^{\circ} \mathrm{C}\right) \mathrm{e}$ velocidade do ar constante $1,00 \mathrm{~m} . \mathrm{s}^{-1}$. O experimento foi realizado em triplicata para cada temperatura. A primeira bandeja do secador (de baixo para cima) foi reservada para sílica-gel, a fim de manter a umidade do ar controlada, enquanto que as amostras foram expostas, em camada delgada, na segunda bandeja. Tais amostras foram retiradas periodicamente do secador e pesadas em balança semi-analítica (SSR$600^{\circledR}$ ) com 4 casas decimais, alternando sempre a posição das amostras dentro do desidratador. Esse procedimento perdurou até que fosse alcançado o equilíbrio dinâmico entre a amostra e o ar de secagem (peso constante com variação máxima de $0,05 \mathrm{~g}$ ). Ao final desse processo, as amostras foram submetidas à estufa a vácuo $\left(25 \mathrm{lbf} / \mathrm{in}^{2}\right)$ a $70^{\circ} \mathrm{C} / 24$ horas, para determinação do peso seco.

As folhas de $L$. rigida Benth., depois de submetidas ao processo de secagem, foram trituradas por quatro minutos em liquidificador (Mallory ${ }^{\circledR}$ ) com posterior peneiramento (40 mesh), a fim de obter granulometria uniforme. Após esta etapa, o pó das folhas (PF) foi acondicionado em recipientes de vidros (50g), envoltos com alumínio, identificados, ao abrigo da luz e temperatura ambiente.

$\mathrm{O}$ pó obtido nas temperaturas de $40^{\circ} \mathrm{C}, 50^{\circ} \mathrm{C}$ e $60^{\circ} \mathrm{C}$ foram submetidos as análises quanto ao teor de cinzas, umidade, proteínas, lipídios e carboidratos por diferença (BRASIL, 2008 [11]). Para a determinação do valor calórico foi utilizado o Fator de Atwater. Destaca-se que todos esses resultados foram expressos em média \pm desvio-padrão.

Todos os dados coletados foram anotados e tabulados ao decorrer da pesquisa, sendo que os dados referentes aos experimentos físico-químicos e nutricionais foram submetidos à análise estatística aplicando-se o teste de variância (ANOVA) One Way e o teste de Tukey para verificar se houve diferença significativa entre os tratamentos. Para isto, foi utilizado o Assistat Software versão $7.7 \mathrm{com}$ os valores de $p<0,05$.

\section{RESULTADOS E DISCUSSÃO}

A Tabela 1 apresenta as características físico-químicos e nutricionais encontradas nas folhas e pó de folhas de oiticica, nos diferentes tempos de secagem. 
Tabela 1 - Caracterização físico-química e nutricional da folha de oiticica

\begin{tabular}{|l|c|c|c|}
\hline \multicolumn{1}{|c|}{ Parâmetros } & $\mathbf{4 0}^{\circ} \mathbf{C}$ & $\mathbf{5 0}^{\circ} \mathbf{C}$ & $\mathbf{6 0}^{\circ} \mathbf{C}$ \\
\hline Umidade (\%) & $7,80 \pm 0,15^{\mathrm{b}}$ & $7,89 \pm 0,35^{\mathrm{b}}$ & $7,01 \pm 0,07^{\mathrm{b}}$ \\
\hline Cinzas (\%) & $10,24 \pm 0,64^{\mathrm{a}}$ & $10,16 \pm 0,62^{\mathrm{a}}$ & $10,64 \pm 0,18^{\mathrm{a}}$ \\
\hline Lipídios (\%) & $5,96 \pm 1,22^{\mathrm{a}}$ & $4,42 \pm 0,75^{\mathrm{a}}$ & $7,34^{\mathrm{b}} \pm 1,19^{\mathrm{a}}$ \\
\hline Proteínas (\%) & $0,58 \pm 0,03^{\mathrm{a}}$ & $0,54 \pm 0,02^{\mathrm{a}}$ & $0,58 \pm 0,02^{\mathrm{a}}$ \\
\hline Carboidratos (\%) & 75,42 & 78,17 & 74,43 \\
\hline Valor energético (Kcal) & 357,64 & 354,62 & 366,1 \\
\hline
\end{tabular}

O teor de umidade em uma amostra determina a capacidade de conservação, propagação microbiológica e ocorrência de reações químicas. A redução do teor de água livre em produtos de origem vegetal tem como consequência a minimização da disponibilidade de água para o crescimento de microrganismos, evitando assim alterações químicas indesejáveis para o armazenamento dos produtos [12].

Ao observar os dados de umidade da folha in natura, as três condições de secagem reduziram significativamente o teor de umidade, alcançando valores dentro do máximo de $14 \%$ permitidos para farinhas pela $\operatorname{RDC} \mathrm{n}^{\circ} 263$, que dispõe o regulamento técnico para produtos de cereais, amidos, farinhas e farelos [13]. Os percentuais encontrados nesse experimento encontram-se inferiores aos observados por Alves e Portela [14], ao estudarem o pó da folha de moringa, obtida a diferentes temperaturas, onde obtiveram valores de 8,53 $\pm 0,30 ; 8,92 \pm 0,09$ e 9,41 $\pm 0,22$ para secagens à $40^{\circ} \mathrm{C}, 50^{\circ} \mathrm{C}$ e $60^{\circ} \mathrm{C}$, respectivamente.

O resíduo mineral fixo representa o percentual de matéria mineral presente no produto [15]. Com relação a esse parâmetro, o percentual encontrado nas folhas de oiticica in natura, representa um valor significativo, ultrapassando o percentual encontrado nas folhas de couve flor e brócolis, observados por [16], que observaram valores de $1,38 \pm 0,00^{a}$ e $0,80 \pm 0,00^{a}$, respectivamente. Nota-se ainda, que os valores de resíduo mineral fixo para os pós obtidos a diferentes condições de temperatura, estatisticamente não diferem significativamente $(p<0,05)$, toda via, encontram-se muito superiores ao encontrado na folha in natura. Isso explica-se pelo fato de o processo de secagem propiciar a concentração do valor nutritivo dos produtos devido à perda de água [8]. Almeida et al. [17] e Marques et al. [18], verificaram, respectivamente, o percentual de cinzas sobre plantas medicinais e a caracterização físico-química das folhas de Bauhinia forficata, encontraram resultados que variaram de 10 a $8 \%$ do material seco na mesma proporção de amostra.

Para carboidrato, encontraram-se valores significativos, estando entre $74,43 \%$ a $78,17 \%$, todavia, ressalta-se que nesses valores estão inclusos o valor de fibra bruta, uma vez que não foi possível determinar esse parâmetro. Sabe-se que a fibra é um nutriente que exerce várias funções benéficas ao organismo humano e os vegetais são ótimas fontes desse nutriente. [19] analisaram a composição nutricional de folhas, 
talos, cascas e sementes de vegetais, e nesse estudo os autores obtiveram os valores de 0,96 para as folhas de couve-flor, 0,72 em folha de beterraba, 1,26 em folhas de brócolis e 1,58 em folhas de cenouras.

Com relação a lipídios, observa-se que o pó seco à temperatura de $60{ }^{\circ} \mathrm{C}$ apresenta maior concentração deste macronutriente. O percentual de lipídios encontrados nesse estudo assemelha-se ao encontrado por Piekarski e Waszszynskyj [20] ao estudar o pó da folha de abóbora, encontrando um percentual de 4,99\%.

O fruto da planta oiticica é apontado com potencial para produção de biodiesel [21-22]. A planta oiticica (Licania rigida George Bentham) apresenta um considerável teor de lipídios na sua composição, segundo Bayma e Lorenzi e Matos [23-5], que descrevem a extração de óleos do fruto da planta como importante fonte de renda no sertão do nordeste brasileiro em meados anos de 1930 a 1950.

Para proteínas, o percentual encontrado na matéria seca nas três temperaturas são semelhantes entre si, não havendo diferença significativa das amostras, conforme a estatística $(p<0,05)$. Os resultados mostram valores menores que a literatura, onde Gasqui et al. e Pedro et al. [24-25], em suas pesquisas sobre a caracterização química e físico-química da farinha de Moringa oleifera Lamarck e a composição centesimal de plantas medicinais, respectivamente, encontraram nas suas amostras secas os valores para proteína entre 2 e $9 \%$, enquanto o encontrado na folha de oiticica encontrou-se valores iguais de 0,58.

Observa-se ainda, que o produto possui um significante aporte calórico, assemelhando-se ao encontrado por Gupta et al., [26], ao estudar folhas de curcubita maxima, observando um valor de $336,57 \mathrm{Kcal}$.

Ressalta-se ainda, que a composição centesimal dos vegetais pode ser influenciada pela espécie, grau de maturação, condições de cultivo, estação do ano e pela parte da planta analisada, como também pelas condições de colheita, dessa forma podendo vim a modificar a matéria tanto qualitativamente quanto quantitativamente [27].

\section{CONCLUSÃO}

Dessa forma, conclui-se que as diferentes temperaturas de secagem não apresentaram influencia com relação às características nutricionais do pó, e que ambas as condições de secagem resultaram em produtos com características adequadas, conforme as legislações especificas. Porém, a temperatura de $60^{\circ}$ mostrou-se uma opção bastante interessante, visando o seu custo benefício. Sendo assim, evidencia-se a importância de buscar novas formas de introduzir esse produto alimentício, seja como complemento ou substituição à dieta da população brasileira.

\section{REFERÊNCIAS}

[1] FERREIRA, S. N.; SAMPAIO, M. J. A. M. Biodiversidade e conhecimentos tradicionais associados: implementação da legislação de acesso e repartição de benefícios no Brasil. Brasília, DF: Sociedade Brasileira para o Progresso da Ciência, 2013. 356p.

[2] FIRMINO, W. C. A.; MENEZES, V. J. M.; PASSOS, C. E. C.; DIAS, C. N.; ALVES, L. P. L.; DIAS, I. C. L.; NETO, M. S.; OLEA, R. S. G. Contexto histórico, uso popular e 
concepção científica sobre plantas medicinais. Cadernos de Pesquisa, São Luís, v. 18, n. especial, p. 90-95, dez. 2011.

[3] DINIZ, F. O.; MOREIRA, F. J. C.; SILVA, F. D. B.; MEDEIROS FILHO, S. Influência da luz e temperatura na germinação de sementes de oiticica (Licania rigida Benth.). Revista Ciência Agronômica, Fortaleza, v. 39, n. 3, p. 476-480, jul. 2008.

[4] MELO, J. C.; TEIXEIRA, J. C.; BRITO, J. Z.; PACHECO, J. G. A.; STRAGEVITCH, L. Produção de Biodiesel de Óleo de Oiticica. 2010. Disponível em: <http://www.biodiesel.gov.br/docs./congresso2006/producao/Oiticica14.pdf>.

[5] LORENZI, H.; MATOS, F. J. A. Plantas Medicinais no Brasil - Nativas e Exóticas, 2. ed. Nova Odessa, São Paulo; Instituto Plantarum, 2002.

[6] CANO-CHAUCA, M.; RAMOS, A. M.; STRINGHETA, P. C.; MARQUES, J. A.; SILVA, P. I. Curvas de secagem e avaliação da atividade de água da banana passa. Boletim do Centro de Pesquisa de Processamento de Alimentos, Curitiba, v. 22, p. 121-132, jan./jun. 2004.

[7] MARTINAZZO, A. P.; MElO, E. C.; RESENDE, O. ; CORRÊA, P. C. Análise e descrição matemática da cinética de secagem de folhas de capim-limão. Revista Brasileira de Engenharia Agrícola e Ambiental, Campina Grande, v. 11, p. 301306, jun. 2007.

[8] CELESTINO, S. M. C. Princípios de Secagem de Alimentos. 1. ed. Planaltina DF: Embrapa Cerrados, 2010. 51p.

[9] FEMENIA, A.; SERRANO, G.S.; SIMAL, S.; GARAU, M.C.; EIM, V.S.; ROSSELLÓ, C. Effects of air-drying temperature on the cell walls of kiwifruit processed at different stages of ripening. Food Science and Technology, Campinas, v. 42, n. 1, p. 106112, jul. 2009.

[10] PARK, K. J.; YADO, M. K. M.; BROD, F. P. R. Estudo de secagem de pêra bartlett (Pyrus sp.) em fatias. Ciência e Tecnologia de Alimentos, Campinas, v. 21, n. 3, p. 288-292, set./dez. 2001.

[11] BRASIL. Ministério da Saúde. Secretária de Vigilância Sanitária. Resolução RDC $n^{\circ} 263$ de 22 de setembro de 2008. Aprova o regulamento técnico para produtos de cereais, amidos, farinhas e farelos. Diário Oficial da União. Poder Executivo, de 23 de setembro de 2008.

[12] SANTANA, M. C. C. B.; MACHADO, B. A. S.; SILVA, T. N.; NUNES, I. L.; DRUZIAN, J. I. Incorporação de Urucum como aditivo em embalagens biodegradáveis a base de quitosana. Ciência Rural, Santa Maria, v. 43, n. 3, p. 544-550, abr./out.2013.

[13] BRASIL. Ministério da Saúde. Secretária de Vigilância Sanitária. Resolução RDC $n^{\circ} 263$ de 22 de setembro de 2005. Aprova o regulamento técnico para produtos de cereais, amidos, farinhas e farelos. Diário Oficial da União. Poder Executivo, de 23 de setembro de 2005.

[14] ALVES, C. J.; PORTELA, F. V. J. Pó da folha da moringa oleifera: estudo tecnológico da obtenção do pó, caracterização físico-química, tecnológica e de compostos bioativos. Resumo expandido. XXIV Seminário de Iniciação Cientifica VII seminário de Desenvolvimento Tecnológico e Inovação. Anais. Teresina-PI. Universidade Federal do Piauí, 2015.

[15] ZARDO, F. P. Análises Laboratoriais para o controle de qualidade da farinha de trigo. 2010. 56 f. Trabalho de Conclusão de Curso (Monografia) - Instituto Federal 
de Educação, Ciência e Tecnologia Rio Grande do Sul - Campus Bento Gonçalves, Bento Gonçalves, 2010.

[16] MÜCKE, L. R.; MASSAROLO, L. P.; MÜCKE, N. Estudo comparativo da qualidade de vegetais in natura e minimamente processados por meio da avaliação de parâmetros físico-químicos. $73 \mathrm{f}$. Trabalho de Conclusão de Curso (Monografia) - Universidade Tecnológica Federal do Paraná. Medianeira, 2012.

[17] ALMEIDA, M. M. B.; LOPES, M. F. G.; SOUSA, P. H. M.; NOGUEIRA, E. M. D.; MAGALHÃES, C. E. C. Determinação de umidade, fibras, lipídios, cinzas e sílica em plantas medicinais. Boletim Centro de Pesquisa e Processamento de Alimento, Curitiba, v. 21, n. 2, p. 343-350, jul./dez. 2003.

[18] MARQUES, G. S.; LYRA, M. A. M.; PEIXOTO, M. S.; MONTEIRO, R. P. M.; LEÃO, W. F.; XAVIER, H. S.; SOARES, L. A. L.; NETO, P. J. R. Caracterização fitoquímica e físico-química das folhas de Bauhinia forficata Link coletada em duas regiões brasileiras. Revista de Ciências Farmacêuticas Básica e Aplicada, Araraquara, v. 33, n. 1, p. 57-62, ago. 2012.

[19] STORCK, C. R.; NUNES, G. L.; OLIVEIRA, B. B.; BASSO, C. Folhas, talos, cascas e sementes de vegetais: composição nutricional, aproveitamento na alimentação e análise sensorial de preparações. Ciência Rural, Cuiabá, v. 43, n. 3, p. 537-543, abr. 2013.

[20] PIEKARSKI, F. V. B. W.; WASZSZYNSKYJ, N. Folha de abóbora (Curcubitam moschata): caracterização físico-química, conteúdo mineral e propriedades reológicas para fins de panificação. Revista da Sociedade Portuguesa de Ciências da Nutrição e Alimentação, Porto, v. 15, n. 1, p. 30-39, ago. 2009.

OLIVEIRA, F. A. G.; PINTO, V. L.; SOUZA, L.; DINIZ, J. C.; SANTOS, A. G. D.; VIANNA, F. A. Síntese, caracterização e avaliação de biodiesel de óleo de oiticica [21] Licania rigida Benth) e isolalamento do éster metílico do ácido licânico. Revista Química: Ciência, Tecnologia e Sociedade, Natal, v. 1, n. 1, p. 31-41, mar. 2012.

[22] QUEIROGA, V. P.; FREIRE, R. M. M.; MARINHO, D. R. F.; ALMEIDA, F. A. C.; MELO, B. A. Composição química e mineral de amêndoas de oiticica em três tempos de armazenamento. Revista Verde de Agroecologia e Desenvolvimento Sustentável, Pombal, v. 8, n. 2, p. 173-177, abr./jun. 2013.

[23] BAYMA, C. Oiticica. Rio de Janeiro: Serviço de Informação Agrícola do Ministério da Agricultura, 1957. 140p.

[24] GASQUI, D. L.; MARINELLI, P. S.; ALDA, M. M. B.; TANAKA, A. S. O. Caracterização química e nutricional da farinha de moringa (Moringa oleifera Lam.).

Revistas Científicas Eletrônicas, São Paulo, v. 4, n. 1, p. 01-09, abr. 2015.

[25] PEDRO, F. G. G.; ARRUDA, G. L.; OLIVEIRA, J. C.; SANTOS, A. D.; SIGARINI, K. S.; HERNANDES, T.; VILLA, R. D.; OLIVEIRA, A. P. Composição centesimal e mineral de plantas medicinais comercializadas no mercado do Porto de Cuiabá, Mato Grosso, Brasil. Revista Brasileira de Plantas Medicinais, Campinas, v. 18, n. 1, p. 297-306, jul./dez. 2016.

[26] GUPTA, S.; LAKSHMI, J. A. A.; MANJUNATH, M. N.; PRAKASH, J. Analysis of nutrient and antinutrient content of underutilized green leafy vegetable. Food Science and Technology, Campinas, v. 38, n. 4, p. 339-345, jun. 2005.

[27] MARQUES, G. S.; LYRA, M. A. M.; PEIXOTO, M. S.; MONTEIRO, R. P. M.; LEÃO, W. F.; XAVIER, H. S.; SOARES, L. A. L.; NETO, P. J. R. Caracterização fitoquímica e físico-química das folhas de Bauhinia forficata Link coletada em duas regiões 
brasileiras. Revista de Ciências Farmacêuticas Básica e Aplicada, Araraquara, v. 33, n. 1, p. 57-62, ago. 2012. 